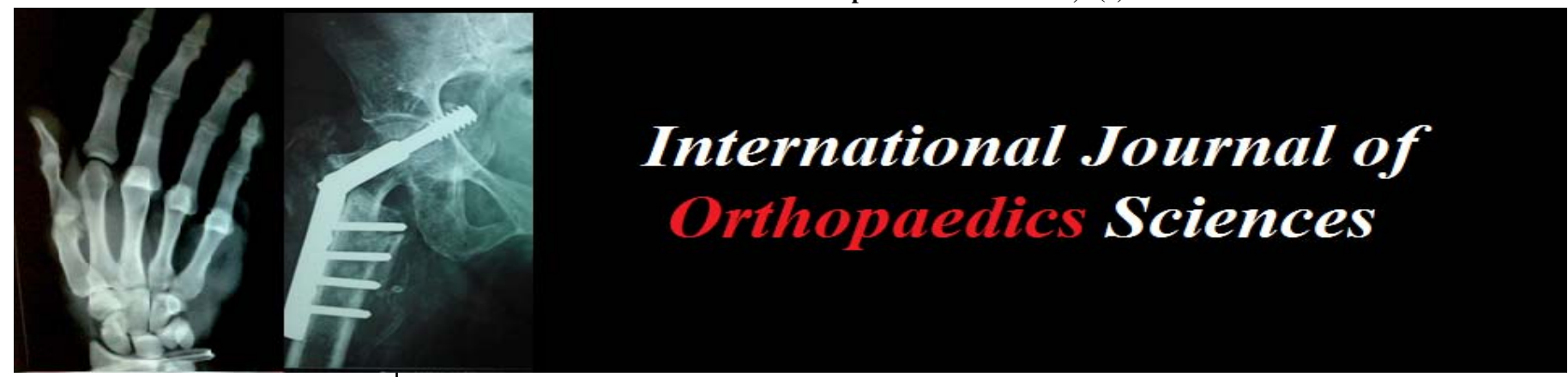

ISSN: $2395-1958$

IJOS 2018; 4(2): 01-05

(C) 2018 IJOS

www.orthopaper.com

Received: 01-02-2018

Accepted: 02-03-2018

Mohammed Ibrahim

Gulbarga Institute of Medical

Sciences, Karnataka, India

Dr. Vijay H Rathod

Gulbarga Institute of Medical

Sciences, Karnataka, India

\section{A clinical study of minimal invasive anterior bridge plating for humerus shaft fractures}

\author{
Mohammed Ibrahim and Dr. Vijay H Rathod
}

DOI: https://doi.org/10.22271/ortho.2018.v4.i2a.01

\section{Abstract}

Introduction: In humeral shaft fractures management anterior bridge plating is reported as an acceptable less traumatic and reproducible procedure by several authors. Our study done to evaluated the clinical, radiological, and functional outcome of such fractures in 10 patients, all of which were managed with dynamic compression plate over an average follow up period of 16 months. Though open reduction and plating technique of humerus shaft fracture is gold standard, this technique also gives good outcome.

Materials and Methods: Ten patients with humerus shaft fractures were managed by anterior bridge plating using Minimum invasive osteosynthesis technique between Jan 2016 and April 2017 were included in this study. All cases were treated with closed reduction and $4.5 \mathrm{~mm}$ dynamic compression plate fixation over anterolateral aspect in bridging mode using the MIPO technique. The dominant side, gender ratio, surgery time, radiation exposure, and fracture union time, and complications were noted. The UCLA shoulder and Mayo elbow performance scores were used for assessing the shoulder and elbow function.

Results: Out of the ten patients in the study, seven were males and three were females. The mean age was 38 years (range 24 to 60 years). seven out of ten patients (70\%) had the dominant side fractured. Mean surgical time in minutes was 80min (range: 60-100 minutes) and mean radiation exposure, in terms of one sec for each c-arm exposure was 88 seconds (range: 60-140 seconds).The mean fracture union (radiological) time was 11.6 weeks (range: 10-18 weeks). However Shoulder function was excellent to good in 9 cases (90\%) and fair in 1 case (10\%) on the UCLA score.

Conclusion: There is high rate of union and excellent functional outcomes by this procedure. Minimal incision with this anterior bridge technique for fracture shaft humerus results in good functional outcomes and should be considered as an effective surgical option in the treatment of humeral shaft fractures. It is a safe and less time consuming method for simple types of humeral shaft fractures when the surgeon is experienced in the technique.

Keywords: Anterior bridge plate, Diaphyseal humerus fracture

\section{Introduction}

Near normal acceptable reduction and rigid stable fixation has its biological advantage as compare to absolute anatomical reduction with compromising soft tissue and vascularity ${ }^{[1]}$. Biological fixation of fractures with soft tissue preservation and near acceptable reduction is becoming a more acceptable entity. However it is to be evaluated. For a satisfactorily outcome only union is not the only requirement but early and acceptable functional usage of the limb is the goal. Therefore concept of biological fixation was developed over a stable mechanical fixation ${ }^{[2]}$. This has evolved the development and improvement in the techniques of biological fracture fixation and stabilization systems ${ }^{[3,4]}$. From conservative cast and braces ${ }^{[5,6]}$ to internal fixation with intramedullary interlocking nailing ${ }^{[7]}$, ORIF with plate and screw. Treatment of humeral fracture has evolved a lot with their complications. Studies are still going on to prove superiority of one over another ${ }^{[7-10]}$. Minimally invasive technique for humerus shaft fracture has shown promising results recently ${ }^{[11-14]}$. This study have evaluated the clinical, radiological, and functional outcomes of this mini invasive technique for humerus fracture over a minimum follow-up of 18 months.

\section{Materials and Methods}

Ten patients with fractures of humerus shaft were treated with Minimum invasive Anterior Bridge plating technique in a case series of study between Jan 2015 and April 2017 at our
Dr. Vijay $H$ Rathod Gulbarga Institute of Medical Sciences, Karnataka, India 
centre. The cases were followed for a period of 18 months. Patients who had fractured at in the middle one third shafts were included. These fractures were reduced and fixed with 4.5mm locking compression plate (LCP). Institutional Ethical Committee approved the study. The inclusion criterion included all fracture of humerus middle one third shafts between 20 and 55 years and who consented to participate. The operative procedure was performed within 3 days of the injury. Exclusion criteria included fracture on both the limbs, higher grade of compounding, concomitant other medical illness such as malignancy, vascular insufficiency of the upper limb, poly trauma patients, drug addict patients (alcohol and others). A preoperative clinical examination of the affected arm was carried in all aspects like abrasions, swelling, contusion, puckering and neurovascular deficit (chiefly Radial nerve status). Antero posterior (AP) and lateral (Lat) radiographs of the humerus, of the patient were evaluated (Fig no1). These radiographs were also used to decide the appropriate length of implant and planning the surgery. Functional outcome where analyzed by UCLA shoulder score and Mayo elbow score (table no 1\&2).

\section{Surgical Technique}

The patients were positioned supine. All patients were given local brachial block with ultrasound guided. A Distally, a 2-3 $\mathrm{cm}$ incision at the lateral border of the biceps, nearly $5 \mathrm{~cm}$ proximal to the flexion crease. Retraction of biceps was done to expose the musculocutaneous nerve, overlying the brachialis muscle. The nerve is then retracted and brachialis muscle was split till bone. The lateral half of brachialis muscle then protects radial nerve. A sub-brachialis, extra-periosteal tunnel was created with long stripper then a 2-3 cm incision between the medial border of deltoid and proximal biceps, $5 \mathrm{~cm}$ caudal to the acromion process was made, 4.5-mm dynamic compression plate is passed through the incision on the anterior surface of the humerus from distal incision. Varus/ valgus angulation, length and rotation are restored by traction. Confirmation of the reduction done under image intensifier. Each side of the plate is fixed with two screws in anterior to posterior direction. During the the process of making tunnel atmost care is take to be in anteriorplane of humerus to prevent iatrogenic damage to radial nerve. The amount of force required to be used for manual traction for achieving proper reduction was not easy at first, but becomes easy as technique is practiced. The 'cortical step sign' as described by Krettek ${ }^{[15]}$ is used to look for any rotational malalignment. The operative time (skin incision to closure) and duration of radiation exposure (in seconds) was recorded. Postoperatively, shoulder immobilizer was applied.

\section{Follow Up}

The operative limb was kept in shoulder immoblizer till stitches were removed (12th day), there after the patients were advised to perform active gentle limb range of motion exercises as their pain control permits. The immoblizer was continued for another one week. However they were informed to take out the limb and perform informed exercise for 10-15 minutes after every hour. Post operative xray (Fig no 2) and one month x-ray and 3 month x-ray (Fig no 3) where take in follow up. To avoid stiffness, after four weeks they were trained by a dedicated physiotherapist to perform active range of motion exercises and were allowed to perform usual gentle activities. After radiological signs of healing, a rehabilitation program was started. The aim was to gain full mobility, muscular strengthening and proprioception as soon as possible. The total rehabilitation period depends on the individual patient's progression. The final goal is to restore ache free functional to full range of motion and strength. The union time and complications were noted. The patients were followed up by same surgeon, first after 2 weeks then monthly for the next 3 months, then once every 6 months till 18months. The patients shoulder and elbow function were analyzed using the UCLA shoulder score18 and the Mayo elbow performance score (MEPS)19 The UCLA shoulder score was graded into excellent to good ( $>27$ points), fair to poor $\left(<5^{\circ}\right.$ of varus/ valgus angulation intra operatively and on following these patients up ${ }^{[16,17]}$, in 1 of the cases the angulation had remodeled to acceptable alignment. On determining the functional outcome of other cases, 9 cases had excellent (Fig no 4\&5) to good and one fair outcome ${ }^{[18]}$.

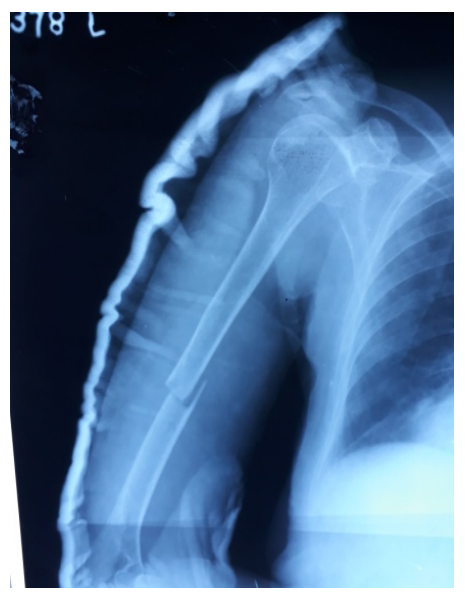

Fig 1

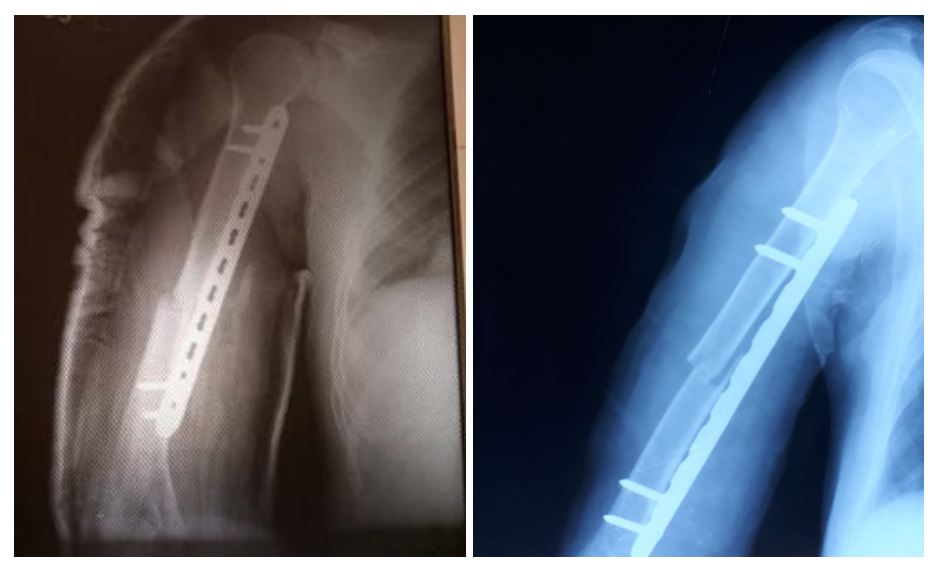




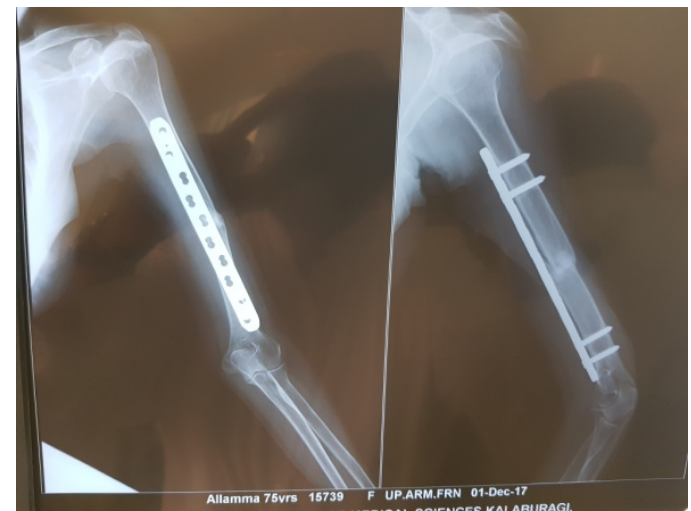

Fig 3
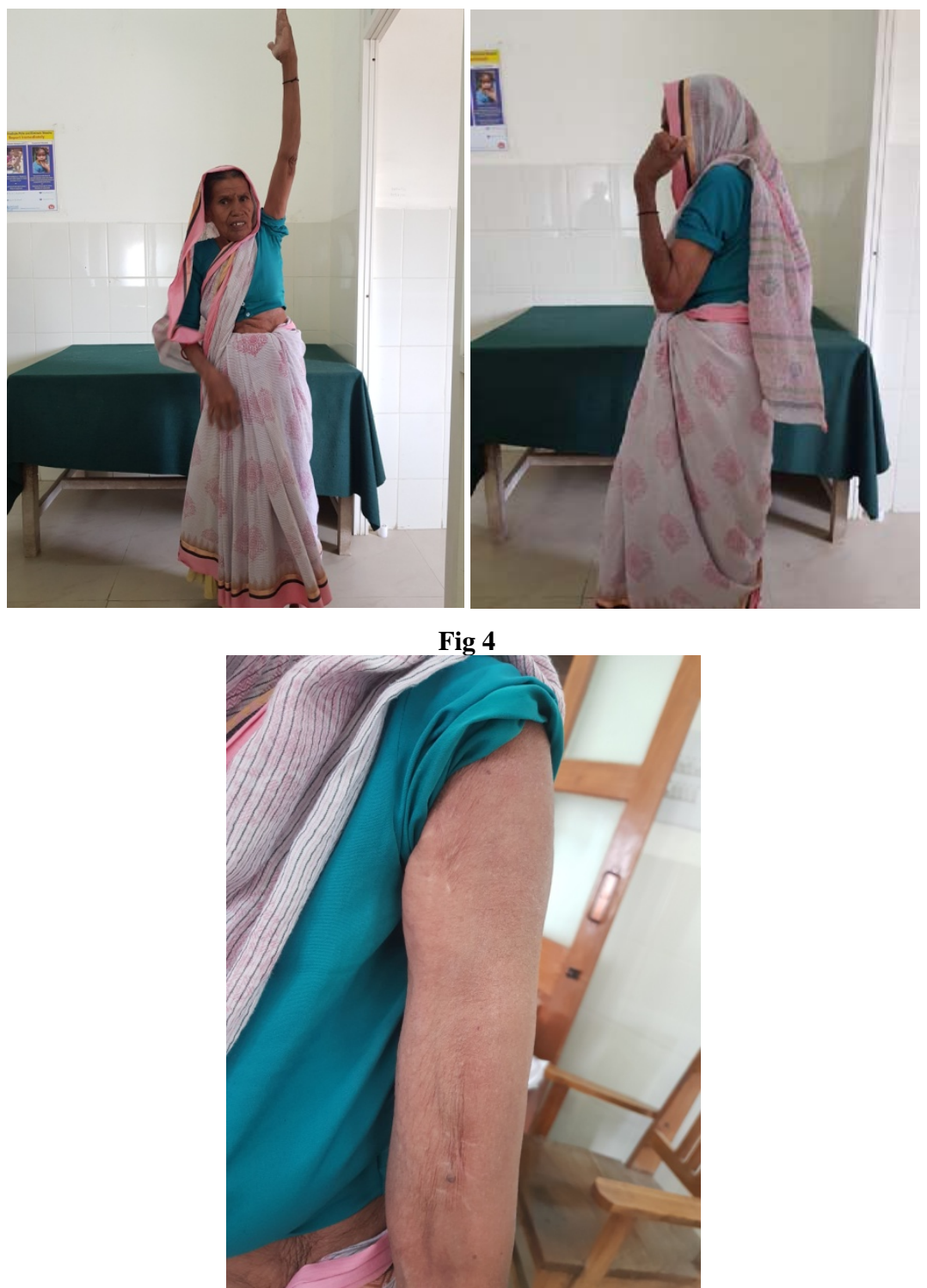

Fig 5

\section{UCLA Shoulder Rating Scale}

Table 1

\begin{tabular}{|c|c|c|}
\hline Measure & Finding & Points \\
\hline Pain & no pain & 10 \\
\hline & occasional and slight pain & 8 \\
\hline & pain with heavy or particular activities only; uses salicylates occasionally & 5 \\
\hline & none or little at rest; occurs with light activities; salicylates frequently & 4 \\
\hline & constant but bearable; strong medications occasionally & 2 \\
\hline & constant, unbearable; strong medications frequently & 1 \\
\hline & normal activities & 10 \\
\hline Function & slight reduction in function; able to work above shoulder level & 8 \\
\hline
\end{tabular}




\begin{tabular}{|c|c|c|}
\hline & most housework, washing hair, putting on brassiere, shopping, driving & 5 \\
\hline & light housework or most daily living activities (ADL) & 4 \\
\hline & very light activities only & 2 \\
\hline & unable to use arm & 1 \\
\hline muscle power and motion & normal muscle power; motion near normal & 10 \\
\hline & muscle power good or normal; elevation $140^{\circ}$; external rotation $20^{\circ}$ & 8 \\
\hline & muscle power fair to good; elevation $90^{\circ}$; internal rotation $90^{\circ}$ & 5 \\
\hline & muscle power poor to fair; elevation less than $60^{\circ}$; internal rotation $<45^{\circ}$ & 4 \\
\hline & ankylosis with good functional position & 2 \\
\hline & ankylosis with deformity & 1 \\
\hline & & \\
\hline Score for Each Measure & Interpretation & \\
\hline $10(>8)$ & Excellent & \\
\hline $8(>6)$ & Good & \\
\hline 4 or $5(>4)$ & Fair & \\
\hline 1 or $2(<3)$ & Poor & \\
\hline
\end{tabular}

Mayo Elbow Performance Score (MEPS)

Table 2

\begin{tabular}{|c|c|c|}
\hline 1 & Pain & $0-45$ (no pain -sever pain \\
\hline 2 & Stability & $0-10$ (grossly unstable-stable) \\
\hline 3 & Morbidity & $0-20\left(<50^{0}, 100^{0}\right.$ ) \\
\hline 4 & Daily functional activity & 0 -25(none possible-normal function for 5 different \\
\hline & Excellect & $>90$ \\
\hline & Good & $75-89$ \\
\hline & Fair & $60-74$ \\
\hline & Poor & $<60$ \\
\hline
\end{tabular}

\section{Discussion}

Tscherne and Krettek first reported minimal invasive osteosynthesis for fractures in $1996^{[19]}$. Since then this technique is used in managing various other fractures. Despite the requirement of high surgical expertise and time taken for adaptation of the procedure, the MIPO technique seems to be reproducible and applicable in almost all types of shaft humeral fractures. Lower rates of iatrogenic nerve injury with minimal bone vascularity disruption, and soft tissue dissection are all the advantages over conventional plate technique. Though indirect reduction and plate placement is technically difficult and requires experience, Plates can be safely used anteriorly or anteromedially over the humeral shaft. Bridging the fracture fragment, with fixation only at either ends of the plate and bone. Excellent to good results have been achieved with sub brachialis plating with no major soft tissue problems and with functional results as per other methods ${ }^{[20]}$. Open technique of plating interferes with the local vascularity, leading to osteonecrosis underneath the plate, which may cause delayed healing to non healing (published rate of nonunion being 5.8\%) ${ }^{[21]}$. Union of the humeral shaft fractures in this series presents good results with fixation through indirect reduction aims at maintaining bone alignment through mini incision and replacing absolute stability by relative stability. This bridgeplate technique can be used even for the treatment of humeral shaft nonunion (both atrophic and hypertrophic nonunion) ${ }^{[22]}$. The present technique through its less tissue dissection and periosteal stripping makes a promising modality of treatment. In conclusion, this series demonstrates that the anterior minimally invasive bridge-plate technique for treatment of humeral shaft fractures presents newer, effective, cosmetically advanced (minimal operative site scar) and acceptable modality of treatment for such fractures. Though the technique is complex, requiring a relatively long learning time the results are good and reproducible. However a larger multi centric metanalytical study with control groups will help us to arrive at a standardize protocol. To conclude, MIPO is definitely a newer and acceptable modality of treatment.

\section{Reference}

1. Frigg R, Wagner M. AO Manual of fracture management. Chapters 1.2: Concepts of fracture fixation, 2006.

2. Baumgaertel F, Buhl M. Fracture healing in biological plate osteosynthesis. Injury, 1998; 29 (Suppl 3):C3-6.

3. Dickson KF, Munz JW. Biomechanics and biology of Locked plating: Tech Orthop, 2007; 22:4.

4. Wagner M, Frenk A. Locked plating: Biomechanics and biology and locked plating: Clinical indications. Tech Orthop 2007; 22:4.

5. Camden P. Fracture bracing of the humerus. Injury 1992; 23:245-8.

6. Hunter SG. The closed treatment of fractures of the humeral shaft. Clin Orthop Relat Res. 1982; 164:192-8.

7. Chao TC et al. Humeral shaft fractures treated by DCP, Ender and interlocking nails. Int Orthop, 2005; 29:88-91.

8. Ajmal M, et al. Antegrade locked intra medullary nailing in humeral shaft fractures. Injury, 2001; 32:692-4.

9. Petsatodes G, et al. Antegrade interlocking nailing of humeral shaft fractures. J Orthop Sci, 2004; 9:247-52.

10. Santori FS, Santori N. The Exp Nail for the treatment of diaphyseal humeral fractures. JBJS Br. 2002; 84(Supp 3):280.

11. Apivatthakakul T, et al. MIPO of the humeral shaft fracture: Is it possible? A cadaveric study and preliminary report. Injury, 2005; 36:530-8.

12. Zhiquan A, et al. Minimally invasive plating osteosynthesis (MIPO) of middle and distal third humeral shaft fractures. J Orthop Trauma, 2007; 21:628-33.

13. Ziran $\mathrm{BH}$, et al. Percutaneous plating of the humerus with locked plating: Technique and case report. J Trauma In j Infect Crit Care, 2007; 63:205-10.

14. Livani B, et al. Is MIPO in humeral shaft fractures really safe? Postoperative ultra sonographic evaluation. Int 
Orthop, 2009; 33:1719-23.

15. Krettek C, et al. Intra operative control of axes, rotation and length in femoral and tibial fractures- Technical note. Injury. 1998; 29(Suppl 3):C29-39.

16. Amstutz HC, Sew Hoy AL, Clarke IC. UCLA anatomic total shoulder arthroplasty. Clin Orthop Relat Res 1981; 155:7-20.

17. Morrey BF, An KN, Chao EY. Functional evaluation of the elbow. In: Morrey BF, editor. The elbow and its disorders. 2nd ed. Philadelphia: W. B. Saunders; 1993, 86-97.

18. Livani B, Belangero WD. Bridging plate osteosynthesis of humeral shaft fractures. Injury, 2004; 35:587-595. doi: 10.1016/j. injury. 2003.12.003.

19. Krettek C, Schandelmaier P, Tscherne H. Distal femoral fractures: Transarticular reconstruction, percutaneous plate osteosynthesis and retrograde nailing [in German]. Unfall chirug, 1996; 99:2-10.

20. ShantharamShetty M, Ajith Kumar M, Sujay KT, Abhishek Kini R, KanthiKiran G. Mminimally invasive plate osteosynthesis for humerus diaphyseal fractures, Indian Journal of Orthopaedics, 2011, 45(6).

21. Paris $\mathrm{H}$, et al. Fractures of the shaft of the humerus: Systematic plate fixation: Anatomic and functional results in 156 cases and a review of the literature. Rev Chir Orthop Reparatrice Appar Mot, 2000; 86:346-59.

22. Paulo Roberto Vilaca Jr., Marcelo Koh Uezumi: Anterior minimally invasive bridge-plate technique for treatment of humeral shaft non union: J Orthopaed Traumatol 2012; 13:211-216. 